\title{
Small but Mighty: Cell Size and Bacteria
}

\author{
Petra Anne Levin ${ }^{1}$ and Esther R. Angert ${ }^{2}$ \\ ${ }^{1}$ Department of Biology, Washington University, St. Louis, Missouri 63130 \\ ${ }^{2}$ Department of Microbiology, Cornell University, Ithaca, New York 14853 \\ Correspondence: plevin@wustl.edu; eangert@cornell.edu
}

Our view of bacteria is overwhelmingly shaped by their diminutive nature. The most ancient of organisms, their very presence was not appreciated until the 17th century with the invention of the microscope. Initially, viewed as "bags of enzymes," recent advances in imaging, molecular phylogeny, and, most recently, genomics have revealed incredible diversity within this previously invisible realm of life. Here, we review the impact of size on bacterial evolution, physiology, and morphogenesis.

$\mathrm{H}$ umanity has always experienced the impact of microorganisms, most obviously through their ability to cause devastating disease. For the vast majority of human history, we were unaware of their presence, much less the fundamental microbial processes to which we owe our existence: from the production of energy by our ancient bacterial endosymbionts (the mitochondria) to the generation of oxygen in our atmosphere. Despite their astounding global abundance $\left(\sim 10^{30}\right.$ cells $)$ and their substantial contribution to the total biomass of planet earth (Whitman et al. 1998; Kallmeyer et al. 2012), our inability to see these tiny life forms shrouded their nearly limitless diversity in mystery. It was not until the 17th century, with the careful observations and reports of Anton van Leeuwenhoek, that we became aware of this previously invisible world on and around us. Today, we know that there are more bacteria living in our intestinal tract than stars in the Milky Way galaxy (and that they far outnumber all the people who have ever lived). We also know now that we thrive because of their meta- bolic support. Although less than 1\% of bacteria can be cultured readily in the laboratory (Amann et al. 1995), the biochemical versatility among these tiny creatures exceeds that of the plants, animals, and fungi combined (Pace 1997).

Anton van Leeuwenhoek's illustrations in a letter to the Royal Society of London in the late 17 th century provide one of the earliest records of bacterial cell form (Dobell 1960). Viewed through a single lens, Leeuwenhoek pioneered studies of the human microbiome, describing motile bacilli, cocci, and spirochetes he found in scrapings taken from between his teeth (and the teeth of others). This triumph was made possible by incomparable curiosity, lens construction, and exceptional lighting. The simple cellular structure and glassy nature of most unstained bacteria viewed with a light microscope generated little interest in bacterial cell biology with the exception of objects of unusual contrast, such as endospores described by Robert Koch and the wonderfully colorful and large cyanobacteria. The bacterial nature of the latter was itself only appreciated late in the 20th cen-

Editors: Rebecca Heald, Iswar K. Hariharan, and David B. Wake

Additional Perspectives on Size Control in Biology: From Organelles to Organisms available at www.cshperspectives.org

Copyright (C) 2015 Cold Spring Harbor Laboratory Press; all rights reserved; doi: 10.1101/cshperspect.a019216

Cite this article as Cold Spring Harb Perspect Biol 2015;7:a019216 
P.A. Levin and E.R. Angert

tury (Oren 2004). For the most part, bacteria were viewed as primitive "bags of enzymes" until the 1990s, when the complexity of bacterial subcellular structure and regulators of cell reproduction finally began to emerge. Tools and reagents developed for eukaryotic cell biology (e.g., stains for DNA, membranes, and fluorescent protein tags), once applied to bacterial cells, revealed astonishing insights including the specific and even dynamic localization patterns of proteins, and the accuracy of chromosome organization.

\section{BACTERIAL SIZE RANGE}

Bacillus subtilis, Staphylococcus aureus, Escherichia coli, and Caulobacter crescentus, the primary models for bacterial cell biology, are more or less typical in size, with individual cell vol-

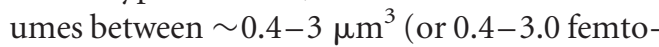
liters; femtoliter or $\mathrm{fL}$ is equal to $10^{-15} \mathrm{~L}$ ). Freeliving marine ultramicrobacteria, appropriately named Candidatus Actinomarina minuta, have an average cell volume $\sim 1 \%$ that of $E$. coli $\left(0.013 \mu \mathrm{m}^{3}\right.$, range $0.6 \times 10^{-2}$ to $2.4 \times$ $\left.10^{-2} \mathrm{fL}\right)$. At the other end of the spectrum, the marine sediment-dwelling Thiomargarita namibiensis, the "Sulfur pearl of Namibia," is a spherical organism with a volume eight orders of magnitude more than that of E. coli $\left(\sim 750 \mu \mathrm{m}\right.$ in diameter, volume $2.2 \times 10^{8} \mathrm{fL}$ or $0.22 \mu \mathrm{L})$. Thiomargarita is slightly larger than a Drosophila eye (Schulz et al. 1999) and big enough to be seen by the human eye (Fig. 1). A closer look at Thiomargarita reveals a centrally located fluid-filled vacuole, which takes up $\sim 98 \%$ of the cell volume and is a nitrate reservoir used to fuel sulfide oxidation. Even when accounting for the intracellular vacuole, a large Thiomargarita cell has a tremendous biovolume to support ( $\left.\sim 4.4 \times 10^{6} \mathrm{fL}\right)$. Epulopiscium spp., intestinal symbionts of certain marine surgeonfish, are the largest known heterotrophic bacteria. These cigar-shaped cells are up to $600 \mu \mathrm{m}$ $\times 80 \mu \mathrm{m}$ with an active cytoplasmic volume of $\sim 2 \times 10^{6} \mu \mathrm{m}^{3}$ or $0.02 \mu \mathrm{L}$ (Angert et al. 1993) . Unlike Thiomargarita, Epulopiscium cells contain no storage vacuoles or other inert inclusions (Fig. 1). The difference in size between Candidatus Actinomarina minuta and these giants is equivalent to the difference between a mouse and the Empire State Building (E. coli could be represented by a small skunk or a rabbit on this scale). We refer the reader to Niklas (2015), wherein he discusses how cell features and geometry factor into considerations of cell size.

What limits bacterial cell size? The smallest cells need enough volume to accommodate adequate genetic resources to support the cell's lifestyle (Koch 1996). The cell must also contain the basic machinery required to express those
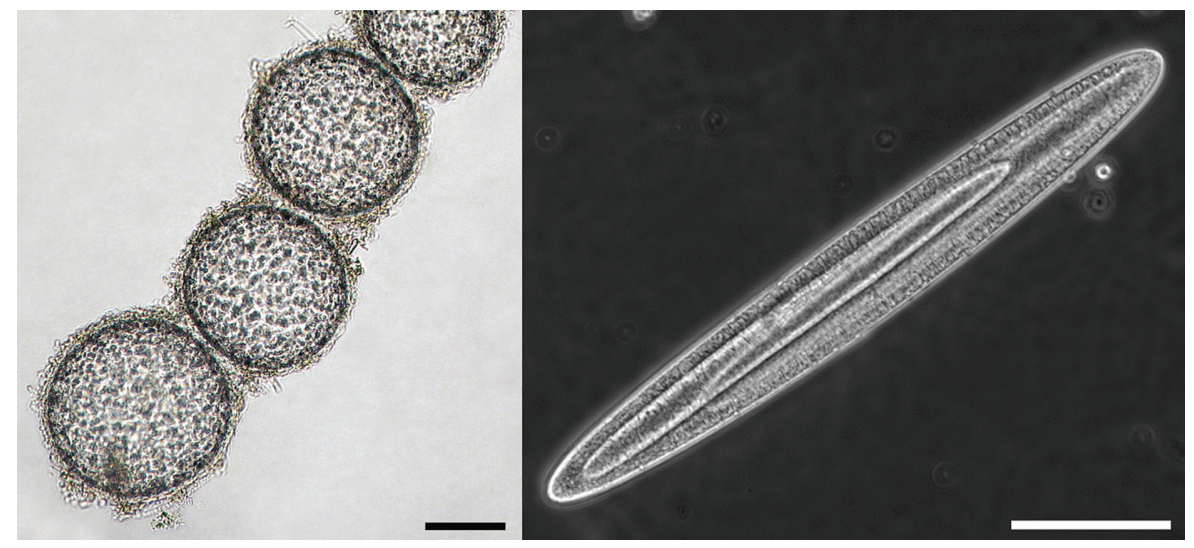

Figure 1. Giant bacteria. On the left is a chain of Thiomargarita namibiensis cells. In this bright-field image, sulfur granules can be seen in the cytoplasm. The panel on the right shows an exceptionally large Epulopiscium cell with two large internal offspring. Scale bars, $100 \mu \mathrm{m}$. 
genes as well as housekeeping proteins and biochemicals to maintain its metabolism and cellular reproduction. Genomic and metabolic streamlining is seen in obligate intracellular symbionts, pathogens, and organelles that have given up metabolic capabilities because those needs are supplied by the host (McCutcheon and Moran 2012; Wernegreen 2012). The loss of genes for sensing environmental change and responding to those contingencies can allow for substantial genome reduction but not always a corresponding reduction in cell size.

The structure and function of all large cells appear bounded by the limits of diffusion (Schulz and Jorgensen 2001). Encounters with nutrients, elimination of waste, and the timely movement of biomolecules within the cell to support metabolic needs all impact the ability of a large bacterium to survive in its environment. The compartmentalization of cellular functions, the motor protein-facilitated trafficking over a complex cytoskeletal network, the expansion of genomic resources, and the acquisition of endosymbionts that became energy-generating organelles have all been credited for the advancement of the size and complexity of eukaryotic cells (Angert 2012).

\section{THE PROBLEM OF DIFFUSION}

The identification of giant bacteria required a reexamination of the long-held beliefs about maximum bacterial cell size. For all cells, growth and reproduction is limited by the speed of chemical communication and the availability of nutrients to fuel metabolism. Diffusion is the random, three-dimensional movement of a molecule. For movement of molecules inside a cell, it is the most efficient means of transport over a short distance of a few microns. Even a large protein can reliably traverse this distance in the cytoplasm in much less than a second. Thus, a biomolecule synthesized or entering a typical bacterium has a high probability that it will reach its site of activity almost instantly. But considering a small distance by our scale, across a gap of a millimeter-approximately the length of an Epulopiscium cell and a fraction of the circumference of Thiomargarita-diffusive trans- port becomes numbingly unreliable. A small molecule like oxygen at room temperature would typically take about an hour to diffuse $1 \mathrm{~mm}$ (Schulz and Jorgensen 2001). Similarly, the acquisition of nutrients relies on diffusion and capture of molecules at the surface of a cell. Consequently, free-living cells tend to be small, with a large surface area relative to their cytoplasmic volume, so that capture of nutrients, at low concentrations, can support the cell's metabolic needs. Cell form and function have been subjected to these constraints. For comparison, E. coli has a surface-area-to-volume ratio of $\sim 3.7 \mu \mathrm{m}^{2}$ to $1 \mu \mathrm{m}^{3}$, whereas the largest Thiomargarita cell has a surface-to-volume ratio of $8.2 \times 10^{-3} \mu \mathrm{m}^{2}$ to $1 \mu \mathrm{m}^{3}$. Clearly, these large bacteria are bending the rules.

\section{How Epulopisicum Has Overcome} the Issue of Diffusion

Most large bacteria either maintain a high surface-to-volume ratio by being long and thin like Spirochaeta plicatilis (a 250- $\mu \mathrm{m}-\mathrm{long}$, 0.75 - $\mu \mathrm{m}$-diameter corkscrew-shaped bacterium) or adopt a morphology in which no part of the cytoplasm is much more than a micron away from the external environment. Thiomargarita is an example of the latter, maintaining a thin layer of cytoplasm surrounding a large fluid-filled vacuole. Epulopiscium spp. are the exception to this rule.

Although their elongated form undoubtedly helps increase their surface-area-to-volume ratio (Koch 1996), the largest Epulopiscium has a ratio of $0.6 \mu \mathrm{m}^{2}$ to $1 \mu \mathrm{m}^{3}, \sim 1 / 6$ that of E. coli. Despite this difference, Epulopiscium maintains a high metabolic rate. Epulopiscium spp. use a number of other structural modifications to advance cell size. Epulopiscium cells have a highly invaginated cell membrane that may compensate for the small apparent surface area of the cell envelope (Angert 2006). Large Epulopiscium spp. are covered with flagella and are highly motile, which helps the cell maintain its position in the gut in proximity to a plentiful supply of nutrients. The coordinated rotation of flagella helps stir the surrounding medium, facilitating movement of molecules across the cell 
surface, refreshing the immediate environment. In this way, Epulopiscium is able to reduce reliance on diffusion of molecules down a concentration gradient. Transporters located on the infolded cell membrane likely facilitate the capture of nutrients.

Epulopiscium cells show extreme polyploidy throughout their life cycle, an adaptation that may also contribute to their ability to attain such a large mass (Ward et al. 2009). Polyploidy is a common feature of large cells. Examples from eukaryotes include endoreduplication in Drosophila salivary cells and, as discussed in Czesnick and Lenhard (2015), plant cells with specialized functions including trichomes, the fine hairlike appendages visible on the leaves and stems of certain species. Gillooly and colleagues (2015) discuss a potential role for endoreplication and increases in nuclear DNA content as a determinant of size in human cells. Large bacteria, however, have taken polyploidy to an extreme level (Angert 2012). Although the Epulopiscium chromosome is fairly typical in size $(\sim 4 \mathrm{Mb})$, each cell contains tens of thousands to hundreds of thousands of copies (Mendell et al. 2008). In contrast to most bacteria, in which the highly organized chromosome or "nucleoid" occupies almost the entire cytoplasm, Epulopiscium nucleoids are located at the periphery of the cytoplasm (Fig. 2). This is likely an important organizational feature that allows Epulopiscium to respond immediately to environmental stimuli. It may also accommodate the growth of internal offspring cells (described below).

\section{REPRODUCTION AMONG THE GIANTS}

Large bacteria show diverse reproductive strategies, some of which may help to maximize their reproductive potential as well as the production and release of large offspring. All of the largest Epulopiscium spp. reproduce once daily, forming two or more intracellular offspring. Surprisingly, internal offspring initiation and development follows a predictable daily cycle and any given population inside a host fish is well synchronized with respect to development. Offspring growth occurs during the day and coincides with times when the host is feeding.

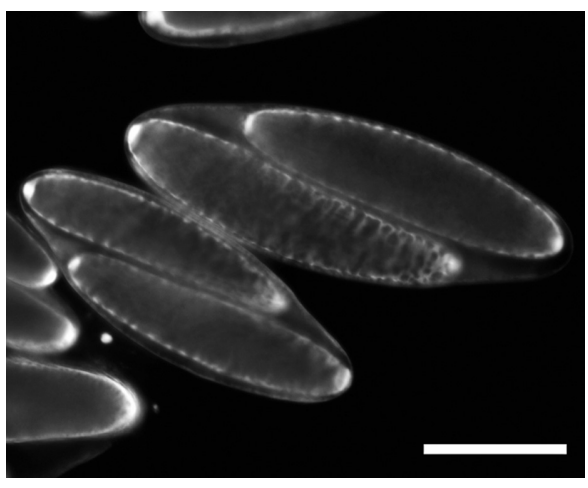

Figure 2. DNA in Epulopiscium sp. type B. This cluster of Epulopiscium cells is stained with the DNA dye DAPI. Each of the two large mother cells at the center of this field contains two large offspring. DNA is located at the periphery of the cytoplasm in mother cells and offspring. At this late stage of development, the mother-cell DNA is difficult to see because much of it has degraded. Offspring cells contain brightly stained polar structures; these are the start of "granddaughter cells." Scale bar, $100 \mu \mathrm{m}$.

Reproduction begins with bipolar division of the mother cell. The polar cells are fully engulfed and these offspring then grow inside a membrane-bound compartment in the mother-cell cytoplasm, until they completely fill the mother cell. At a late stage of development, the mother cell appears to undergo a form of programmed cell death, a process that likely conserves the biochemical resources accumulated during growth (Ward et al. 2009). In the final stages, offspring emerge through a split in the mother cell envelope. Despite developmental synchrony, inhabitants of a single population vary in volume by as much as a factor of five (Mendell et al. 2008).

Because of their size, unusual methods of reproduction and the difficulty in determining evolutionary relationships among microbes based on phenotypic characteristics, Epulopiscium was originally classified as a novel protist. Molecular phylogeny corrected this oversight, grouping Epulopiscium spp. with the Clostridia (Angert et al. 1993), endospore-forming Grampositive organisms (of the Firmicutes phylum) that include the intestinal pathogen Clostridium difficile, Clostridium perfingens, the cause of 
gangrene, and the foodborne pathogen Clostridium botulinum from which we acquire Botox. Internal offspring production in Epulopiscium spp. arose from endospore formation (Miller et al. 2012). Adapting endospore formation as a mode of reproduction appears to have happened several times in the spore-forming Firmicutes (Angert 2005).

Despite the unusual mode of reproduction shown by Epulopiscium, other giant bacteria use more "pedestrian" strategies. Thiomargarita namibiensis in particular undergoes binary fission in a single plane, arguably the most common mode of reproduction among the bacteria. Thiomargarita cells do not separate, however, remaining instead as chains of cells housed in a common mucus matrix (Fig. 1). At the same time, closely related organisms reproduce using other strategies, which include budding of offspring from a sessile mother cell and the production of multiple internal offspring (Bailey et al. 2011). How reproductive form affects fitness of extremely large bacteria remains to be determined.

\section{THE IMPACT OF ENVIRONMENT ON SPECIES SIZE}

Large bacteria abound in certain environments in which nutrients are consistently available and concentrations are high. We believe that these associations give us some clues as to conditions that can help organisms break free from diffusion limitations on cell size. Giant spirochetes can be found in nutrient-rich sediments and in some intestinal systems, such as the hindgut of termites. Large rod-shaped cells have been seen in intestinal tracts of a number of herbivores. Sulfur-oxidizing bacterial cells like Thiomargarita abound in marine sediments. They are nearly ubiquitously distributed around the globe and carry with them minerals to fuel their respiration. An abundant supply of energy is a common theme in all of these systems and may be a unifying feature. Polyploidy is widespread in bacteria but is expensive to sustain. In nutrient-rich environments or when energy is practically limitless, selection for scaling down to a single copy of the genome may be relaxed and allow poly- ploid microbes to abound. Subsequent modifications to cellular architecture may then accommodate further expansion in size.

\section{CELL-SIZE HOMEOSTASIS}

Under steady-state conditions, isogenic populations of bacteria maintain cell size within surprisingly narrow parameters. Although a histogram of E. coli or B. subtilis cells sampled in mid-exponential phase is biased toward the left, a consequence of the greater number of smaller newborn cells, only in rare cases are the largest organisms more than twice the size of the smallest (Fig. 3).

Like eukaryotes, bacteria initiate and terminate one round of DNA replication for each division event. In contrast to eukaryotes, however, DNA replication, chromosome segregation, and assembly of the division machinery are not discrete events, instead overlapping one another to a greater or lesser degree depending on growth rate (Fig. 4).

Importantly, at fast growth rates supported by nutrient-rich conditions, bacteria are able to maintain interdivision periods less than half the length of time required for replication of their chromosomal DNA. For example, E. coli can double in mass and divide in as few as $20 \mathrm{~min}$; however, even under ideal conditions, replication of the entire 4-Mb E. coli chromosome takes $\sim 60$ min. Rapidly growing cells resolve this apparent conflict by constantly synthesizing DNA and by initiating new rounds of replication before completion of the old one. Such cells may have 4,8 , or even 16 ongoing replication forks (Yoshikawa et al. 1964; Cooper and Helmstetter 1968). Although initiation is restricted to once per division cycle, only one round of replication needs to be completed before division. Within a single division cycle, initiation and termination events, thus, do not necessarily correspond to the same replication fork.

\section{Early Work on Cell-Size Homeostasis}

In 1968, William Donachie proposed that cellsize homeostasis was tied to cell-cycle progression (Donachie 1968). Combining data on Sal- 
P.A. Levin and E.R. Angert

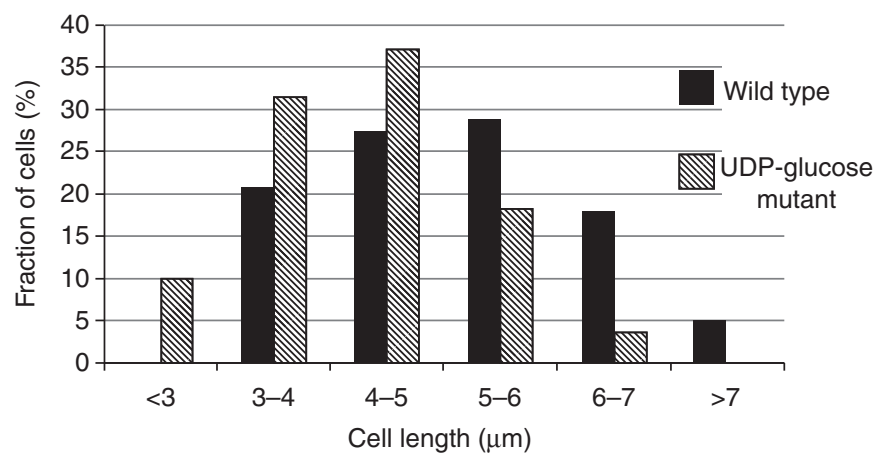

Figure 3. Histogram of Escherichia coli cell size during growth in nutrient-rich medium. The size of wild-type (black) cells is restricted within a narrow twofold range. The graph is biased slightly toward the left owing to the higher number of newborn cells, the consequence of binary fission. UDP-glucose biosynthesis mutants ( $\mathrm{ggm::kan)} \mathrm{(hashed} \mathrm{lines)} \mathrm{are} \mathrm{smaller} \mathrm{than} \mathrm{wild-type} \mathrm{on} \mathrm{average;} \mathrm{however,} \mathrm{the} \mathrm{size} \mathrm{of} \mathrm{these} \mathrm{cells} \mathrm{is} \mathrm{similarly}$ constrained within a twofold range. (Data courtesy of Norbert Hill.)

monella from the Maaløe laboratory with E. coli data from Cooper and Helmstetter (Schaechter et al. 1958; Cooper and Helmstetter 1968), Donachie inferred that bacterial cells initiate DNA replication on achievement of a specific mass. Donachie suggested that the growth-dependent accumulation of a positive acting factor-or inhibition of a negative acting factor-would be sufficient to coordinate the onset of the cell cycle with cell size.
Subsequent work implicated the highly conserved $\mathrm{AAA}^{+}$ATPase DnaA, a dose-dependent activator of DNA replication, in E. coli cell-size control (Løbner-Olesen et al. 1989). Reducing levels of DnaA delays the onset of DNA replication and increases cell size, whereas increasing DnaA levels results in premature initiation and reduced cell size.

On the face of it, tying replication initiation to cell size is an ideal way to correct any defects

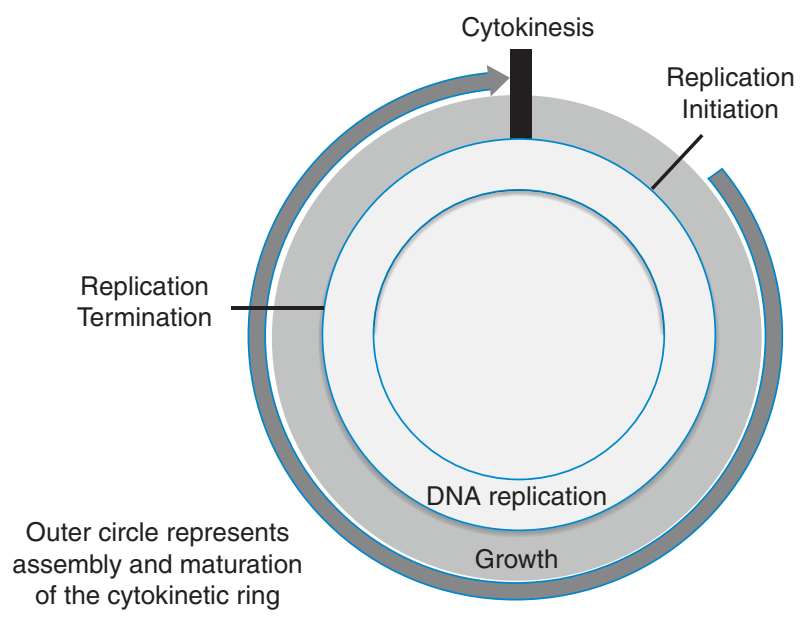

Figure 4. Circular depiction of the cell cycle in rapidly growing (mass doubling time $<60 \mathrm{~min}$ ) bacterial cells. Note that DNA replication and growth are more or less constant-a consequence of multifork replication. A new round of replication is initiated only once per cycle. At least one round of replication must be terminated before division. Although the division machinery is assembled well before cytokinesis (the FtsZ ring is extant for $~ 90 \%$ of mass doubling time in cells cultured in very rich medium), constriction itself takes only a few minutes. 
in cell size early in the cell cycle. Short cells will have to grow longer before they accumulate sufficient DnaA to initiate DNA replication, whereas longer cells will initiate earlier (and thus, at smaller sizes) because critical levels of DnaA are reached earlier in the cell cycle. The observation that in Saccharomyces cerevisiae achievement of a specific size is required before unbudded cells can pass through START at the $\mathrm{G}_{1} / \mathrm{S}$ transition suggests that this type of control may be broadly applicable (Pringle and Hartwell 1981). (Intriguingly, the dnaA gene of Epulopiscium sp. type B encodes an exceptionally long mononucleotide tract, a hot spot for polymerase slippage and potential expression of a truncated and nonfunctional peptide [Mendell et al. 2008]. Although the specific contribution of this unusual gene structure to DnaA regulation is not known, it is possible that it plays a role in increasing Epulopiscium's cytoplasmic volume-to-DNA ratio by reducing DnaA levels and delaying replication.)

Despite the appeal of this model, recent data suggests DnaA accumulation is unlikely to be the sole or even primary determinant of bacterial cell size. Small B. subtilis mutants show wild-type cell-cycle profiles with regard to initiation and DNA replication, suggesting that initiation is independent of cell size in this Gram-positive model organism (Hill et al. 2012). Even in E. coli, in which initiation is highly sensitive to modest changes in the amount of active DnaA (Løbner-Olesen et al. 1989), regulating mass at initiation is only part of the story. Mutations that result in early or delayed initiation appear to adjust their rate of DNA synthesis to compensate for changes in initiation time (Hill et al. 2012). Together, these data suggest the presence of a homeostatic and DnaA-independent mechanism to maintain normal interdivision periods.

\section{Cell Division and Cell-Size Control}

In most bacteria, division is initiated by assembly of the essential GTPase FtsZ into a ring-like structure at the future division site. The "Z-ring" serves as a framework for assembly of the rest of the cell-division machinery.
Structural data suggests that FtsZ is an evolutionary precursor of tubulin, although the two proteins share limited sequence similarity. Approximately one-third of FtsZ in the cell is in the FtsZ ring at a given time with subunit turnover rates on the order of seconds. (For reviews of FtsZ and bacterial cell division, see Erickson et al. 2010 and Lutkenhaus et al. 2012.)

Altering FtsZ levels has a direct impact on cell size, making the cytoskeletal protein an ideal target for factors governing cell-size homeostasis. Depleting FtsZ does not effect cell growth or DNA replication, at least initially, and results in a rapid increase in length. Even modest reductions $(\sim 20 \%)$ in intracellular FtsZ concentration lead to a large increase $(>50 \%)$ in cell length under steady-state conditions (Palacios et al. 1996).

If one imagines the cytokinetic ring as a brick building, then it is easy to see how changes in the supply of bricks would influence cell size. When FtsZ concentration is high, bricks are readily available, reducing transport time and facilitating assembly of a stable and functional Z-ring. However, reductions in available FtsZ slow the transport of bricks to the construction site, delaying assembly of the division machinery and with it cytokinesis. As cells continue to increase in size at normal rates, delays in assembly of the cytokinetic ring translate directly into increases in cell size.

Because FtsZ levels are proportional to cell size in both E. coli and B. subtilis, regardless of growth rate (Weart and Levin 2003), stochastic variations in cell size should be largely mitigated by FtsZ availability. Short cells will require longer periods to accumulate sufficient FtsZ to divide-increasing their size at division. Conversely, longer cells will take less time to accumulate enough FtsZ to support assembly of the division machinery and consequently show shorter interdivision periods reducing daughter-cell length.

Just as DnaA accumulation alone is insufficient to account for cell-size homeostasis, FtsZ accumulation alone is insufficient to trigger division. Although twofold overexpression of FtsZ reduces cell size by $\sim 10 \%$ in both in $E$. coli and B. subtilis, it does not significantly im- 
pact the timing of division (Ward and Lutkenhaus 1985; Weart and Levin 2003; Hill et al. 2012). The inability of excess FtsZ to trigger division suggests the presence of as-yet unidentified factors required to license FtsZ assembly at the nascent division site. How these factors are integrated with cell-cycle progression remains an open question. It is also worth noting that FtsZ is one of many components of the cytokinetic machinery, some of which are also rate limiting for division and, thus, potential candidates for the homeostatic regulators of cell size (Lutkenhaus et al. 2012).

Although a model in which cell-size homeostasis is dependent on accumulation of a ratelimiting cell-cycle component is consistent with what we know about division in E. coli, B. subtilis, and Caulobacter, it is harder to see how it would apply to organisms that divide by budding or tip growth as well as those that show nonlinear growth patterns. Individual E. coli cells elongate at a more or less constant rate under steady-state conditions (Wang et al. 2012). In contrast, Mycobacterium smegmatis tip elongation occurs at different rates depending on whether the cell inherited an old pole that is primed for growth, or a new pole that is not (Aldridge et al. 2012). In cases involving growth asymmetry in daughter cells, other mechanisms must be at play. The mechanisms governing cell-size homeostasis are equally mysterious for those organisms that reproduce by budding, such as Hyphomicrobium, Planctomyces spp., etc.; colonial organisms that adjust ploidy levels and cell length during developmental transitions, such as Streptomycetes; bacteria that uncouple periods of DNA replication and growth from rounds of cytokinesis as in some cyanobacteria and Bdellovibrio; and, finally, those that reproduce by internal daughter-cell production, such as Epulopiscium (Angert 2005).

\section{NUTRIENT-DEPENDENT REGULATION OF CELL SIZE}

Nutrient availability is the primary determinant of cell size in many bacteria. In a classic paper, Schaechter, Maaløe, and Kjeldgaard determined that Salmonella cell size varies as much as twofold depending on growth rate (Schaechter et al. 1958). Cells cultured in nutrient-rich medium with doubling times of $\sim 20$ min were more than twice the size of their counterparts cultured in nutrient-poor medium with mass doubling times well over an hour. Significantly, the relationship between growth rate and size held true regardless of whether growth was slowed by limiting carbon, phosphate, or nitrogen suggested that doubling time-rather than the specific nutrient content of the medium-was the primary determinant of cell size. However, more recent work suggests that bacterial size is a complex phenomenon, dependent on a precisely orchestrated set of regulatory circuits, each responsive to a different and potentially overlapping nutrient-dependent signals.

In E. coli and B. subtilis, UDP-glucose, a nucleotide sugar synthesized in two steps from glucose-6, serves as an intracellular signal for carbon availability and growth rate. Defects in either the phosphoglucomutase required for interconversion of Glc- 6 and Glc- 1 and the pyrophosphorylase responsible for synthesizing UDP-glc from Glc1 reduce E. coli and B. subtilis cell size by as much as 30\% under nutrientrich conditions (Weart et al. 2007; Hill et al. 2013). Consistent with a growth-rate-dependent mechanism, loss of UDP-glc synthesis has little impact on size in cells cultured in nutrientpoor medium. Its proximity to central carbon metabolism makes UDP-glc an ideal signal for carbon availability.

UDP-glucose levels are sensed and transmitted to the division machinery by two, unrelated glucosyltransferases, OpgH and UgtP, in E. coli and B. subtilis, respectively. Although UDP-glucose stimulates interactions among $\mathrm{OpgH}$, UgtP, and FtsZ, the molecular mechanisms by which they function are highly divergent. $\mathrm{OpgH}$ is an integral membrane protein. Genetic and biochemical data suggest that UDP-glc binding drives a conformational change that reveals a binding site for FtsZ. By sequestering FtsZ monomers, OpgH effectively reduces the amount of FtsZ available for assembly into the cytokinetic ring. UgtP, on the other hand, is only transiently associated with the membrane. UgtP interacts with itself or FtsZ in what ap- 
pears to be a mutually exclusive manner. UgtP homo-oligomerization is favored in the absence of UDP-glucose, whereas increases in intracellular UDP-glucose levels during growth in nutrient-rich medium promote interaction with FtsZ (Chien et al. 2013). UgtP levels are high during growth in nutrient-rich medium, but low in nutrient-poor medium, further relieving division inhibition during slow growth (Weart et al. 2007). UgtP inhibits FtsZ assembly but has no impact on GTP hydrolysis, suggesting that it may have an activity similar to microtubule severing proteins like Katanin (Chien et al. 2013).

It is striking that two such evolutionarily divergent organisms (E. coli and B. subtilis are more distantly related than Homo sapiens and $S$. cerevisiae) use UDP-glucose and unrelated glucosyltransferases to help coordinate cell size with growth rate and nutrient availability. $\mathrm{OpgH}$ and UgtP are both "moonlighting" proteins with roles in cell-envelope biogenesis. OpgH takes part in the synthesis of the osmoregulated periplasmic glucans (OPGs), large glucans found in between the inner and outer membranes of Gram-negative bacteria, whereas UgtP synthesizes the Di-Glc-diacylglycerol anchor for lipoteichoic acid, a major anionic component of the Gram-positive cell wall (Lazarevic et al. 2005; Lequette et al. 2008). Both the OPGs and LTAs are thought to play a role in the cellular response to changes in osmolarity, a stress response that leads to a temporary arrest of cell division. Synthesis of OPG or LTA is the primary source of diacylglycerol (DAG) in E. coli and B. subtilis (Zhang and Rock 2008). Although diacylglycerol is a well-studied secondary messenger in eukaryotes, it has not yet been implicated in signaling in bacteria. One possibility is that DAG accumulation serves as a proxy for cell-envelope biogenesis, transmitting information about actual growth rate (rather than nutrient availability) to the division machinery. Intriguingly, FabH, an enzyme responsible for catalyzing an early step in fatty acid biosynthesis, has also been implicated in the nutrientdependent control of cell size; although, whether, FabH plays a direct or indirect role has yet to be established (Yao et al. 2012).
At the same time, carbon availability is unlikely to be the sole determinant of cell size. As Schaechter et al. showed in their seminal 1958 paper, limiting not only carbon, but also other nutrients including nitrogen and phosphate, leads to reductions in both growth rate and cell mass (Schaechter et al. 1958). Moreover, rapidly growing cells defective in UDP-glucose biosynthesis are still significantly larger than their slow-growing counterparts (Weart et al. 2007; Hill et al. 2013). These observations strongly suggest the presence of additional intracellular signaling molecules and cognate sensors, some of which are likely coupled to nitrogen and phosphate utilization, that also contribute to growth rate-dependent increases in cell size.

Precisely why cells increase size in response to nutrient-dependent increases in growth rate is not known. However, analysis of FtsZ ring formation and chromosome segregation in wild-type and short mutant strains suggests that increases in cell size during rapid growth help ensure that there is sufficient room to accommodate the additional DNA generated by multifork replication. Both E. coli and B. subtilis maintain a constant cell-mass-to-DNA ratio regardless of growth rate (Sargent 1975; Donachie and Begg 1989; Sharpe et al. 1998). This appears true for giant bacteria as well (Mendell et al. 2008). Because chromosome segregation and division are not coupled as they are in eukaryotes, defects in bacterial cell size lead to an increase in the frequency of FtsZ rings and division septa over unsegregated nucleoids under conditions supporting rapid growth (Weart et al. 2007; Hill et al. 2013). (Viability is preserved in these cases by DNA transferases that pump chromosomal DNA away from the invaginating septum.)

\section{CONCLUDING THOUGHTS}

As with our appreciation of the vital and diverse roles that bacteria play in the earth's biogeochemical cycles, we are only beginning to understand the molecular and physical forces that govern bacterial size. Cataloging the diverse nature of bacterial life-both in physical and metabolic terms - and characterizing the more 
tractable aspects of their physiology has led to advances in our understanding not only of bacteria, but also fundamental aspects of biology common to all forms of life.

Significantly, mechanisms that have been implicated in the control of cell size in eukaryotes including endoreduplication (reviewed in Lee et al. 2009), nutrient signaling (reviewed in Davie and Petersen 2012), and, of course, cell-cycle control (see reviews by Jorgensen and Tyers 2004; Goranov and Amon 2010) are repeating themes in the control of bacterial cell size. We anticipate that the application of techniques - both the tried and true (e.g., the awesome power of microbial genetics), and the new (e.g., microfluidics [Wang et al. 2012], high-throughput image analysis [Cabeen et al. 2009; Russell et al. 2013], and single-cell metabolomics [Zenobi 2013]) will reveal insights into cell-size control in bacteria that apply to all.

\section{REFERENCES}

${ }^{*}$ Reference is also in this collection.

Aldridge BB, Fernandez-Suarez M, Heller D, Ambravaneswaran V, Irimia D, Toner M, Fortune SM. 2012. Asymmetry and aging of mycobacterial cells lead to variable growth and antibiotic susceptibility. Science 335: 100104.

Amann RI, Ludwig W, Schleifer KH. 1995. Phylogenetic identification and in situ detection of individual microbial cells without cultivation. Microbiol Rev 59: 143-169.

Angert ER. 2005. Alternatives to binary fission in bacteria. Nat Rev Microbiol 3: 214-224.

Angert ER. 2006. The enigmatic cytoarchitecture of Epulopiscium spp. In Microbiology monographs (ed. Shively JM), pp. 285-301. Springer, Berlin.

Angert ER. 2012. DNA replication and genomic architecture of very large bacteria. Annu Rev Microbiol 66: 197212.

Angert ER, Clements KD, Pace NR. 1993. The largest bacterium. Nature 362: 239-241.

Bailey JV, Salman V, Rouse GW, Schulz-Vogt HN, Levin LA, Orphan VJ. 2011. Dimorphism in methane seep-dwelling ecotypes of the largest known bacteria. ISME J 5: 1926-1935.

Cabeen MT, Charbon G, Vollmer W, Born P, Ausmees N, Weibel DB, Jacobs-Wagner C. 2009. Bacterial cell curvature through mechanical control of cell growth. EMBO J 28: $1208-1219$.

Chien AC, Zareh SK, Wang YM, Levin PA. 2013. Changes in the oligomerization potential of the division inhibitor UgtP co-ordinate Bacillus subtilis cell size with nutrient availability. Mol Microbiol 86: 594-610.
Cooper S, Helmstetter CE. 1968. Chromosome replication and the division cycle of Escherichia coli B/r. J Mol Biol 31: 519-540.

* Czesnick H, Lenhard M. 2015. Size control in plant-Lessons from leaves and flowers. Cold Spring Harb Perspect Biol doi: 10.1101/cshperspect.a019190.

Davie E, Petersen J. 2012. Environmental control of cell size at division. Curr Opin Cell Biol 24: 838-844.

Dobell C. 1960. Antony van Leeuwenhoek and his "little animals.” Dover, New York.

Donachie WD. 1968. Relationship between cell size and time of initiation of DNA replication. Nature 219: 1077-1079.

Donachie WD, Begg KJ. 1989. Cell length, nucleoid separation, and cell division of rod-shaped and spherical cells of Escherichia coli. J Bacteriol 171: 4633-4639.

Erickson HP, Anderson DE, Osawa M. 2010. FtsZ in bacterial cytokinesis: Cytoskeleton and force generator all in one. Microbiol Mol Biol Rev 74: 504-528.

* Gillooly JF, Hein A, Damiani R. 2015. Nuclear DNA content varies with cell size across human cell types. Cold Spring Harb Perspect Biol doi: 10.1101/cshperspect.a019091.

Goranov AI, Amon A. 2010. Growth and division-Not a one-way road. Curr Opin Cell Biol 22: 795-800.

Hill NS, Kadoya R, Chattoraj DK, Levin PA. 2012. Cell size and the initiation of DNA replication in bacteria. PLoS Genet 8: e1002549.

Hill NS, Buske PJ, Shi Y, Levin PA. 2013. A moonlighting enzyme links Escherichia coli cell size with central metabolism. PLoS Genet 9: e1003663.

Jorgensen P, Tyers M. 2004. How cells coordinate growth and division. Curr Biol 14: R1014-R1027.

Kallmeyer J, Pockalny R, Adhikari RR, Smith DC, D'Hondt S. 2012. Global distribution of microbial abundance and biomass in subseafloor sediment. Proc Natl Acad Sci 109: 16213-16216.

Koch AL. 1996. What size should a bacterium be? A question of scale. Annu Rev Microbiol 50: 317-348.

Lazarevic V, Soldo B, Medico N, Pooley H, Bron S, Karamata D. 2005. Bacillus subtilis $\alpha$-phosphoglucomutase is required for normal cell morphology and biofilm formation. Appl Environ Microbiol 71: 39-45.

Lee HO, Davidson JM, Duronio RJ. 2009. Endoreplication: Polyploidy with purpose. Genes Dev 23: 2461-2477.

Lequette Y, Lanfroy E, Cogez V, Bohin JP, Lacroix JM. 2008. Biosynthesis of osmoregulated periplasmic glucans in Escherichia coli: The membrane-bound and the soluble periplasmic phosphoglycerol transferases are encoded by the same gene. Microbiology 154: 476-483.

Løbner-Olesen A, Skarstad K, Hansen FG, von Meyenburg K, Boye E. 1989. The DnaA protein determines the initiation mass of Escherichia coli K-12. Cell 57: 881-889.

Lutkenhaus J, Pichoff S, Du S. 2012. Bacterial cytokinesis: From $\mathrm{Z}$ ring to divisome. Cytoskeleton (Hoboken) 69: 778-790.

McCutcheon JP, Moran NA. 2012. Extreme genome reduction in symbiotic bacteria. Nat Rev Micro 10: 13-26.

Mendell JE, Clements KD, Choat JH, Angert ER. 2008. Extreme polyploidy in a large bacterium. Proc Natl Acad Sci 105: $6730-6740$. 
Miller DA, Suen G, Clements KD, Angert ER. 2012. The genomic basis for the evolution of a novel form of cellular reproduction in the bacterium Epulopiscium. BMC Genomics 13: 265.

* Niklas KJ. 2015. A phyletic perspective on cell growth. Cold Spring Harb Perspect Biol doi: 10.1101/cshper spect.a019158.

Oren A. 2004. A proposal for further integration of the cyanobacteria under the bacteriological code. Int J Syst Evol Microbiol 54: 1895-1902.

Pace NR. 1997. A molecular view of microbial diversity and the biosphere. Science 276: 734-740.

Palacios P, Vicente M, Sanchez M. 1996. Dependency of Escherichia coli cell-division size, and independency of nucleoid segregation on the mode and level of ftsZ expression. Mol Microbiol 20: 1093-1098.

Pringle JR, Hartwell LH. 1981. The Saccharomyces cerevisiae cell cycle. In The molecular biology of the yeast Saccharomyces: Life cycle and inheritance (ed. Strathern JN, Jones EW, Broach JR), pp. 97-142. Cold Spring Harbor Laboratory Press, Cold Spring Harbor, NY.

Russell AB, LeRoux M, Hathazi K, Agnello DM, Ishikawa T, Wiggins PA, Wai SN, Mougous JD. 2013. Diverse type VI secretion phospholipases are functionally plastic antibacterial effectors. Nature 496: 508-512.

Sargent MG. 1975. Control of cell length in Bacillus subtilis. J Bacteriol 123: 7-19.

Schaechter M, Maaloe O, Kjeldgaard NO. 1958. Dependency on medium and temperature of cell size and chemical composition during balanced grown of Salmonella typhimurium. J Gen Microbiol 19: 592-606.

Schulz HN, Jorgensen BB. 2001. Big bacteria. Annu Rev Microbiol 55: 105-137.

Schulz HN, Brinkhoff T, Ferdelman TG, Marine MH, Teske A, Jorgensen BB. 1999. Dense populations of a giant sulfur bacterium in Namibian shelf sediments. Science 284: 493-495.
Sharpe ME, Hauser PM, Sharpe RG, Errington J. 1998. Bacillus subtilis cell cycle as studied by fluorescence microscopy: Constancy of cell length at initiation of DNA replication and evidence for active nucleoid partitioning. $J$ Bacteriol 180: 547-555.

Wang P, Robert L, Pelletier J, Dang WL, Taddei F, Wright A, Jun S. 2012. Robust growth of Escherichia coli. Curr Biol 20: 1099-1103.

Ward JE Jr, Lutkenhaus J. 1985. Overproduction of FtsZ induces minicell formation in E. coli. Cell 42: 941-949.

Ward RJ, Clements KD, Choat JH, Angert ER. 2009. Cytology of terminally differentiated Epulopiscium mother cells. DNA Cell Biol 28: 57-64.

Weart RB, Levin PA. 2003. Growth rate-dependent regulation of medial FtsZ ring formation. J Bacteriol 185: 2826 2834.

Weart RB, Lee AH, Chien AC, Haeusser DP, Hill NS, Levin PA. 2007. A metabolic sensor governing cell size in bacteria. Cell 130: 335-347.

Wernegreen JJ. 2012. Strategies of genomic integration within insect-bacterial mutualisms. Biol Bull 223: 112-122.

Whitman WB, Coleman DC, Wiebe WJ. 1998. Prokaryotes: The unseen majority. Proc Natl Acad Sci 95: 65786583.

Yao Z, Davis RM, Kishony R, Kahne D, Ruiz N. 2012. Regulation of cell size in response to nutrient availability by fatty acid biosynthesis in Escherichia coli. Proc Natl Acad Sci 109: E2561-E2568.

Yoshikawa H, O’Sullivan A, Sueoka N. 1964. Sequential replication of the Bacillus subtilis chromosome: III. Regulation of initiation. Proc Natl Acad Sci 52: 973-980.

Zenobi R. 2013. Single-cell metabolomics: Analytical and biological perspectives. Science 342: 1243259.

Zhang YM, Rock CO. 2008. Membrane lipid homeostasis in bacteria. Nat Rev Microbiol 6: 222-233. 


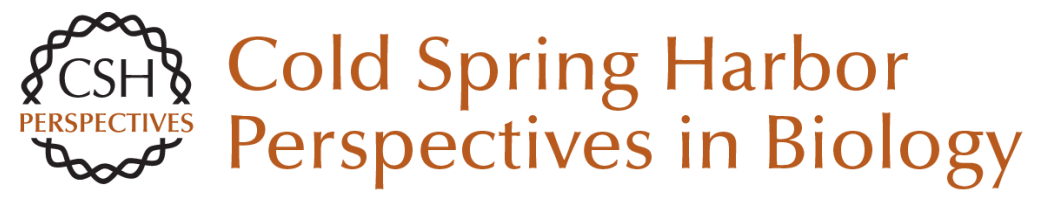

\section{Small but Mighty: Cell Size and Bacteria}

Petra Anne Levin and Esther R. Angert

Cold Spring Harb Perspect Biol 2015; doi: 10.1101/cshperspect.a019216 originally published online June 8, 2015

\section{Subject Collection Size Control in Biology: From Organelles to Organisms}

Cell-Size Control

Amanda A. Amodeo and Jan M. Skotheim

Indeterminate Growth: Could It Represent the

Ancestral Condition?

Iswar K. Hariharan, David B. Wake and Marvalee H. Wake

The Systemic Control of Growth Laura Boulan, Marco Milán and Pierre Léopold

Genome Biology and the Evolution of Cell-Size Diversity

Rachel Lockridge Mueller

Size Scaling of Microtubule Assemblies in Early Xenopus Embryos

Timothy J. Mitchison, Keisuke Ishihara, Phuong Nguyen, et al.

The Influence of Genome and Cell Size on Brain Morphology in Amphibians Gerhard Roth and Wolfgang Walkowiak

The Opposing Actions of Target of Rapamycin and AMP-Activated Protein Kinase in Cell Growth Control

Sravanth K. Hindupur, Asier González and Michael N. Hall

Small but Mighty: Cell Size and Bacteria

Petra Anne Levin and Esther R. Angert
Mechanical Forces and Growth in Animal Tissues Loïc LeGoff and Thomas Lecuit

Biological Scaling Problems and Solutions in

Amphibians

Daniel L. Levy and Rebecca Heald

Intracellular Scaling Mechanisms Simone Reber and Nathan W. Goehring

Growing an Embryo from a Single Cell: A Hurdle in Animal Life Patrick H. O'Farrell

Organ-Size Regulation in Mammals Alfredo I. Penzo-Méndez and Ben Z. Stanger

Size Control in Plants--Lessons from Leaves and Flowers Hjördis Czesnick and Michael Lenhard

Nuclear DNA Content Varies with Cell Size across Human Cell Types

James F. Gillooly, Andrew Hein and Rachel

Damiani

Subcellular Size

Wallace F. Marshall

For additional articles in this collection, see http://cshperspectives.cshlp.org/cgi/collection/

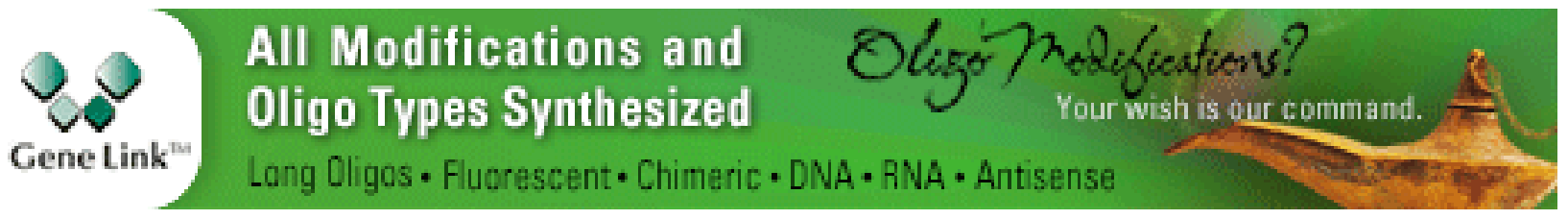

Copyright @ 2015 Cold Spring Harbor Laboratory Press; all rights reserved 